\title{
On the energy economics of air lubrication drag reduction
}

\author{
Simo A. Mäkiharju ${ }^{1}$, Marc Perlin ${ }^{1,2}$ and Steven L. Ceccio ${ }^{1,2}$ \\ ${ }^{I}$ Department of Mechanical Engineering, University of Michigan, Ann Arbor, MI, USA \\ ${ }^{2}$ Department of Naval Architecture and Marine Engineering, University of Michigan, Ann Arbor, MI, USA
}

\begin{abstract}
Air lubrication techniques for frictional drag reduction on ships have been proposed by numerous researchers since the $19^{\text {th }}$ century. However, these techniques have not been widely adopted as questions persist about their drag reduction performance beyond the laboratory, as well as energy and economic cost-benefit. This paper draws on data from the literature to consider the suitability of air lubrication for large ocean going and U.S. Great Lakes ships, by establishing the basic energy economic calculations and presenting results for a hypothetical air lubricated ship. All the assumptions made in the course of the analysis are clearly stated so that they can be refined when considering application of air lubrication to a specific ship. The analysis suggests that, if successfully implemented, both air layer and partial cavity drag reduction could lead to net energy savings of 10 to 20\%, with corresponding reductions in emissions.
\end{abstract}

KEY WORDS: Drag reduction; Air lubrication; Air layer; Partial cavity; Air cavity; Energy cost-benefit; Energy economics.

\section{INTRODUCTION}

Shipping is vital for global commerce, as it is generally one of the most economical and environmentally friendly transportation methods. As approximately $60 \%$ of a typical ship's propulsive power is required to overcome frictional drag, techniques or practices that can significantly reduce a ship's frictional resistance would have a substantial impact both economically and environmentally.

Passive methods of frictional drag reduction (FDR) include application of smooth coatings to the hull to both reduce roughness and inhibit fouling, and textured coatings (e.g. riblets) to modify the turbulent transport near the hull surface. Active methods of FDR include a reduction of the density or viscosity of the fluid near the hull (e.g. bubble drag reduction) or altering the momentum transport in the boundary layer (e.g. polymer injection) (Choi et al., 1996; Proceeding of International Symposium on Seawater Drag Reduction, 1998; 2005).

Within the field of air lubrication there are a variety of techniques that have been suggested since the $19^{\text {th }}$ century (Latorre, 1997). Air lubrication can be divided into three main types: Bubble Drag Reduction (BDR) (Kodama et al. 2000; Madavan et al., 1985); Air Layer Drag Reduction (ALDR) (Elbing et al., 2008); and Partial Cavity Drag Reduction (PCDR) (Butuzov, 1967; Butuzov et al., 1999). Recently Mitsubishi Heavy industries (Mizokami et al., 2010), Stena Bulk (Surveyor, 2011), MARIN (Foeth, 2011), and DK-Group have undertaken serious commercial development of air lubrication. These projects, along with continued fundamental research, are bringing air lubrication methods closer to being widely adopted.

In this paper we will discuss the energy cost-benefits of air lubrication. We will first discuss the different air lubrication techniques, and review data available from laboratory experiments and sea-trials. Next, we setup simplified energy economic calculations followed by an example energy cost-benefit analysis for a chosen generic U.S. Great Lakes 1000 foot ship. We

Corresponding author: Simo A. Mäkiharju

e-mail: smakihar@umich.edu 
show that under appropriate conditions, the energy cost of air delivery is less than the energy savings due to the reduction of friction drag, leading to potential overall propulsive energy saving of $10 \%$ to $20 \%$ for ships with large flat bottoms.

\section{DIFFERENT AIR LUBRICATION TECHNIQUES}

Fig. 1 shows the conceptual differences between the various air lubrication techniques discussed in the following three sections. The five air lubrication regimes are a) Bubble Drag Reduction (BDR), b) Transitional Air Layer Drag Reduction, c) Developed Air Layer Drag Reduction (ALDR), d) Partial Cavity Drag Reduction (PCDR), and e) PCDR with multiple waves in the cavity. Each of these flows is discussed below.

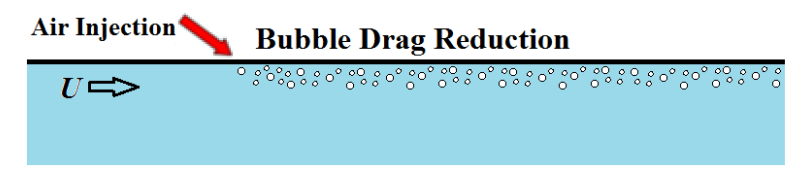

(a)

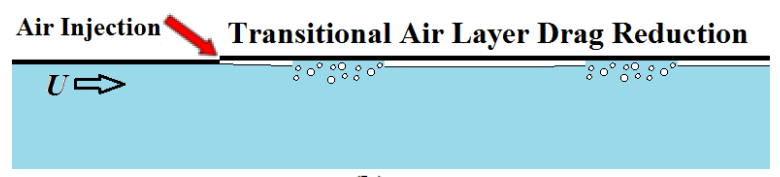

(b)

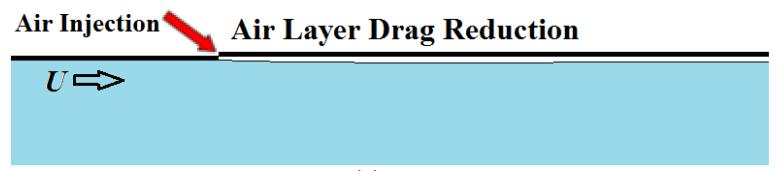

(c)

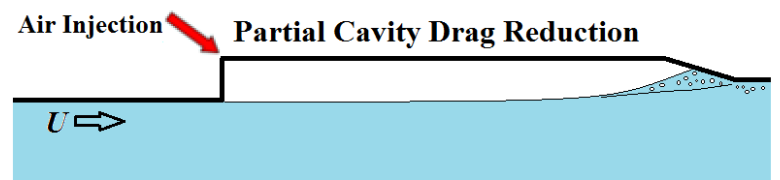

(d)

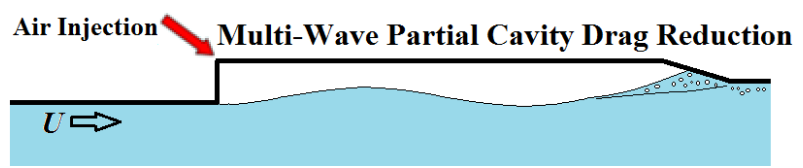

(e)

Fig. 1 Conceptual sketches illustrating the different air lubrication techniques. From the top: BDR, transitional, ALDR, PCDR and multi-wave PCDR.

\section{Bubble drag reduction}

In Bubble Drag Reduction (BDR), gas is injected into the boundary layer, usually through a slot, porous material or a perforated plate. The gas is separated into bubbles that reside predominantly in the boundary layer of the hull. The dispersed bubbles act to reduce the density of the air water mixture and to modify turbulent momentum transport. The technique is sometimes referred to as micro bubble drag reduction, when the bubbles are very small compared to the boundary layer thickness. However, bubbles formed through the turbulent action of the boundary layer are typically no smaller than the Hinze-scale and hence large compared to the inner scales of the turbulent flow. This technique has been the subject of many studies (Madavan et al., 1985; Kodama et al., 2000; Sanders et al., 2006) on both model and meso-scale, and a recent review is provided by Ceccio (2010). The use of BDR for friction reduction of ship hulls is problematic, as the bubbles tend to migrate from the near-wall region of the hull under the influence of local shear and mixing even when the gas is injected beneath a horizontal surface where buoyancy tends to force the bubbles near the wall (Sanders et al., 2006; Elbing et al., (2008). Hence, the persistence of pure BDR is poor, and BDR on ship hulls would require excessive locations for gas injection. 
It is noted that some early applications of air lubrication have been referred to as "bubble drag reduction", even though the type of air lubrication present was not clear. Hence, care should be taken when reading reports that refer to "bubble drag reduction", as they may have entered the transitional or ALDR regions.

\section{Transitional and air layer drag reduction}

When gas is injected beneath a horizontal plate, a transition can take place from a bubbly flow to that of a gas layer. Elbing et al. (2008) showed that a transition will take place in the topology of the air-liquid mixture given a sufficiently high flux of injected air. The first indication of bubble coalescence and persistent drag reduction of $>20 \%$ defines the beginning of the transitional air layer regime. In this region the hull is covered by interwoven regions of bubbly flow and segments of air layer. As the gas flux is increased, the fraction of the surface covered by clusters of fragmented air layer increases, until finally a continuous layer covers the entire surface. Fully developed Air Layer Drag Reduction (ALDR) is considered to be present when the persistent friction drag exceeds $80 \%$. The gas flux required to transition from bubble to transitional and to air layer drag reduction, along with the percentage drag reduction versus air flux are discussed in (Ceccio, 2010; Elbing et al., 2008). The gas flux required for ALDR is shown in Figure 2 where $q$ is the volume flux of injected gas per unit span, and $U$ is the free-stream speed. Data for both smooth and a very rough surface are shown, indicating that a rough surface will require additional gas flux to achieve the same level of friction drag reduction. Note that a backward facing step (with height that can be smaller than the boundary layer thickness) may be necessary to promote boundary layer separation upstream of the injection point to aid in the initial formation of the layer.

A recent sea-trial on the Pacific Seagull was reported on by Hoang et al. (2009), and based on the information provided in this paper, we believe that a transitional or a developed air layer may have formed on the bottom of the hull, rather than the flow remaining in only the BDR region. The ship was $126.6 \mathrm{~m}$ long, $21.4 \mathrm{~m}$ wide and had a 4 and $7 \mathrm{~m}$ draft at ballast and full load conditions, respectively. Overall net fuel savings of $7 \%$ at ballast conditions and $4 \%$ at full-load were reported. (That is $11 \%$ and $6 \%$ drag reduction, for ballast and full load conditions, respectively.) However, the exact injected air volume fluxes were not reported. Local shear stress measurements $50 \mathrm{~m}$ downstream of the gas injector on the hull indicated 20 to $40 \%$ reduction in frictional drag, suggesting the transitional ALDR region as defined in Elbing et al. (2008). A second sea trial, where the transitional or ALDR region may have been achieved, was reported by Mizokami et al. (2010), who obtained 8 to $12 \%$ net energy savings on a ship $162 \mathrm{~m}$ long, $38 \mathrm{~m}$ wide with 4.5 and $6.37 \mathrm{~m}$ draft at ballast and full conditions, respectively. Fig. 2 compares the air fluxes used to those found to be required for ALDR on smooth and rough surfaces in steady flow. These data suggest that, once formed, an air layer can persist for tens of meters along the bottom of a hull.

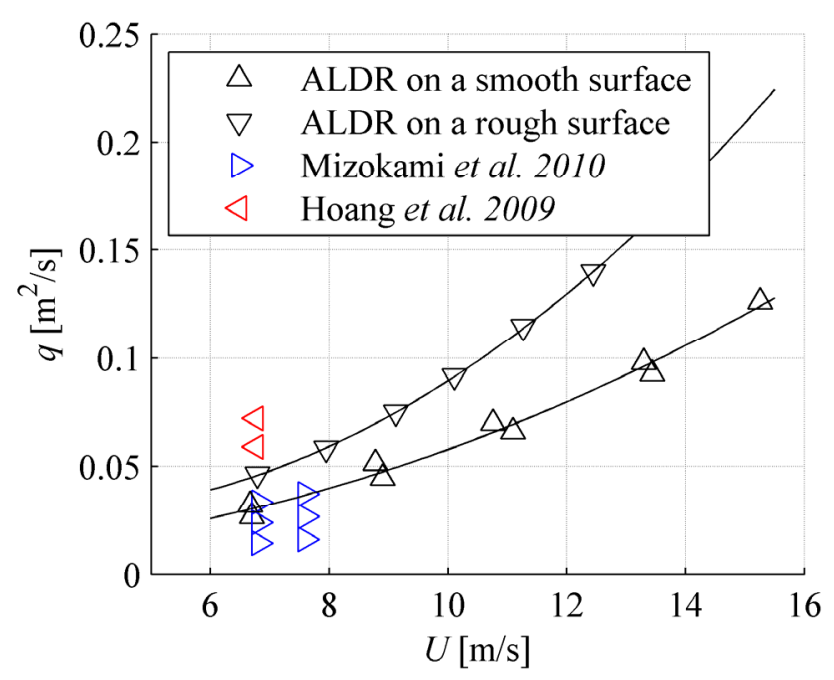

Fig. 2 Air fluxes required for ALDR over rough and smooth surfaces (Elbing et al., 2008), where $q$ is the volume flux of injected gas per unit span on the bottom of a horizontal surface, and $U$ is the free-stream speed. Data for smooth and fully rough surfaces are shown. These data are compared to the approximate air fluxes used in the sea-trials reported by Hoang et al. (2009) and Mizokami et al. (2010). 
When comparing data from sea trials to those from water tunnel experiments as presented in Fig. 2, one should note that the exact gas fluxes and test conditions were not fully available for the sea trials. The sea state, trim of the ship, ship motions, flow around the hull, piping losses, and perhaps unknown limited persistence of the air layer or injector geometry may be some of the factors contributing to the possibility of a transitional, rather than developed ALDR conceivably present in Hoang et al. (2009), despite the significant gas flux. Also, in Hoang et al. (2009) it appears that the gas was injected from the apex of a triangular wedge, and it is conceivable that some of the gas separated into bubbles and was carried away from the hull, thus reducing the effect of the gas as was observed to occur in experiments by Elbing et al. (2008). Additionally, during the authors' previous experiments (Lay et al., 2010) it was observer that the formation of an air layer can be significantly hindered by any random perturbations on the surface upstream of the gas injector. However, an air layer would form at the expected gas fluxes after the addition of a clear separation line in the form of a backward facing step. Lastly it is noted that the experiments (Elbing et al., 2008; Lay et al., 2010) were strictly two-dimensional, while flows around ships are necessarily three-dimensional.

\section{Partial cavity drag reduction}

In Partial Cavity Drag Reduction (PCDR), a recess is created on the bottom of the hull that captures a volume of gas and creates a cavity of air between the hull and outer flow. A backward-facing step on the upstream end and a gently downwardsloping closure on the downstream side normally form the recess that traps the gas, thus forming a ventilated partial cavity. Gas is injected continuously into the cavity to maintain it as some gas is lost due to entrainment at the cavity closure; however with proper cavity design, this gas loss is minimized.

The length of the recess can be close to one-half the streamwise wavelength of the partial cavity (with the trough of the wave occurring at the cavity detachment, and the crest of the wave occurring at or downstream of the cavity closure). Also, it is possible for the recess to extend beyond one wavelength of the cavity surface, making it a multi-wave partial cavity, as in Fig. 1(e), and such a multi-wave cavity could have multiple operating speed ranges which minimize the gas requirements. With a properly designed closure and within a design speed range(s), only a minimal amount of the introduced gas is lost at the cavity closure. The gas separates the solid surface from the liquid resulting in more than a $95 \%$ decrease in frictional drag for the area covered.

Researchers in the former USSR studied PCDR for decades and developed several ships that utilize this method (Butuzov, 1967; Butuzov et al., 1999). These ships are sometimes called air cavity ships (ACS) or ship with artificial cavity (SAC) (Butuzov et al., 1999). In the last decade, there has been renewed interest in air lubrication and many research groups have studied PCDR through numerical modeling (Matveev, 2003), small scale experiments (Arndt et al., 2009; Gokcay et al., 2004), and large scale experiments (Lay et al., 2010; Mäkiharju et al., 2010). A recent review by Ceccio (2010) discusses some of the remaining research questions relevant to PCDR. Most recently, Stena Bulk (Surveyor, 2011) and Maritime Research Institute Netherlands (MARIN) (Foeth, 2011) have presented encouraging results from sea trials on reduced-scale ship models employing PCDR, and the DK-Group has developed a cavity system for ship retrofit.

For PCDR, there are two critical minimum gas fluxes: the initial gas flux to establish the cavity and the flux required to maintain the cavity. Fig. 3 shows the air flux required to establish and maintain a cavity beneath a 12.9 meter long test model, as reported by Mäkiharju et al. (2010). We can observe a region of minimal gas requirements for a single wave cavity of length $9.25 \mathrm{~m}$ over a speed range of $5.3<U<7.1 \mathrm{~m} / \mathrm{s}$ (i.e. $0.56<F r<0.75, F r=U / \sqrt{g L_{\text {cavity }}}$, where $U$ is the flow speed, and $L_{\text {cavity }}$ is the cavity recess length). However, for a multi-wave cavity it might be possible to have multiple minimum gas flux operating regions.

The data presented in Fig. 3 was obtained under steady flow conditions. As most ocean going and U.S. Great Lakes ships operate in conditions where waves are omnipresent and the sea state can be severe, we also need to understand how PCDR performs under perturbed flow. Amromin and Mizine (2003) discuss active flow control for PCDR under perturbed conditions. Partial cavities in perturbed flows were studied in small-scale experiments by Arndt et al. (2009), and at Reynolds number based on downstream distance from air injector of more than $10^{6}$ by Mäkiharju et al. (2010). In the latter, the effect of ambient waves was mimicked by periodically actuating a large flap and thereby causing pressure oscillations as large as $\pm 15 \%$ and velocity fluctuations to $\pm 5 \%$. This led to rapid changes in the cavity length and pressure, and increased maintenance gas flux requirements by as much as a factor of two, with the larger amplitude perturbations requiring a larger excess gas flux. 


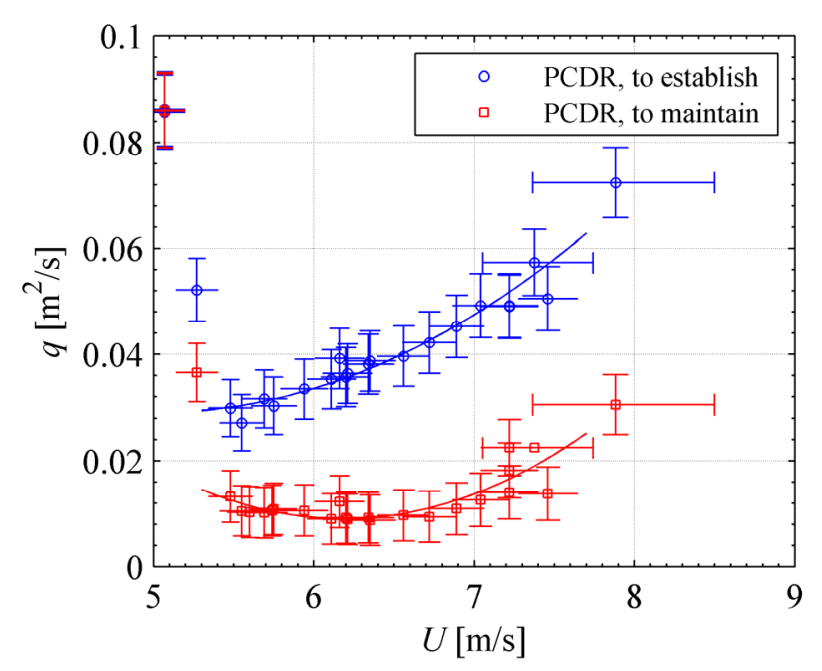

Fig. 3 The minimum gas volume flux per unit span, $q$, required to establish and maintain a ventilated partial cavity as a function of the flow speed (Mäkiharju et al., 2010).

Mäkiharju (2012) discussed scaling of PCDR by comparing data obtained from geometrically similar experiments (a size scale ratio of 14 was used). The results suggested that beyond a critical Reynolds number, the normalized gas flux may be in the same range even at vastly different size scales. If this turns out to be the case, then results from the experiments by Mäkiharju et al. (2010), where $\operatorname{Re} \sim O\left(10^{6}\right)$, could be used to estimate gas fluxes for a full size ship, for which $\operatorname{Re} \sim O\left(10^{9}\right)$.

\section{Summary}

We have concluded that ALDR and PCDR are both air lubrication methods that, when properly applied, can lead to significant reductions in skin friction beneath flat surfaces of a hull. We can estimate the volume flux of air needed to achieve and maintain friction drag reduction based on the data presented in Fig. 2 and 3 for both ALDR and PCDR as reported by Elbing et al. (2008) and Mäkiharju et al. (2010). However, to relate these data to full-scale ships, we must make two considerable assumptions:

- Once an air layer is established we assume that it persists along the entire length of the hull.

- The required gas flux for a multi-wave partial cavity is assumed to be the same as that found for a single wave cavity with similar closure conditions.

Armed with these assumptions, we can proceed to compute the energy costs for delivering the required amount of gas volume flux to the flow and then compare it to the propulsive energy saved via the reduction in friction drag.

\section{ENERGY COST-BENEFIT}

Here we present an energy cost-benefit analysis for ALDR and PCDR on a generic ship with a large flat bottom. The air layer or partial cavity will only reduce the frictional drag on the portion of the hull that is lubricated. We will assume that the ship's form drag is not appreciably changed by the air injector, strakes or other appendages attached to the hull to achieve air lubrication. Based on data of Kawashima et al. (2007) it is assumed that the propulsor efficiency is not significantly altered by the presence of air, as the void fraction of flow entering the propeller is presumably $O(1 \%)$. Furthermore, we will consider only the fraction of the ship's energy consumption for propulsion in order to develop the possible net power savings, $\% P_{\text {saved }}$, compared to the power consumption required to pump the lubricating air:

$$
\frac{\% P_{\text {saved }}}{100} \cong \frac{P_{\text {saved }}}{P_{D} / \eta_{\text {prop }}}
$$


Here $P_{\text {saved }}$ is the net power savings, $P_{\mathrm{D}}$ is the power required to overcome the ship's total drag, $\eta_{\text {prop }}$ is the propeller efficiency. The net power savings can be estimated by considering the reduction in power required to overcome frictional drag on the lubricated surface compared to the power required to supply the gas, yielding

$$
P_{\text {saved }}=\frac{P_{D} f_{F D}}{\eta_{\text {prop }}} \frac{A_{a c}}{A_{\text {wet }}}\left(\frac{\% D_{R}}{100}\right)-\frac{P_{\text {comp }}}{\eta_{\text {elect }}}
$$

Here $\% D_{\mathrm{R}}$ is the percentage frictional drag reduction on the hull covered by air, $f_{\mathrm{FD}}$ is the fraction of total drag due to friction, $A_{\text {ac }}$ area covered by air, $A_{\text {wet }}$ total hull area wetted by water, $P_{\text {comp }}$ is the power required to run the compressor or blower, and $\eta_{\text {elect }}$ is the efficiency of producing the electricity for the compressor/blower relative to the efficiency of providing power for the shaft. Hence a value of one should be used if the ship's propellers are electrically driven, as is the case for ships with Azipods or in general for a ship with integrated electric plants as proposed for U.S. Great Lakes ships by Parsons et al. (2011).

The percentage of total drag due to friction is ship specific and depends also on ship's speed, but we estimate that frictional drag accounts for approximately $60 \%$ of the total drag for Froude numbers less than 0.2 . The Froude number is defined here as $F r=U / \sqrt{g L}$, where $U$ is the ship's speed, $g$ is the gravitational constant $\left(9.81 \mathrm{~m} / \mathrm{s}^{2}\right)$, and $L$ is the overall length of the ship. The power required to overcome frictional drag, $P_{\mathrm{FD}}=P_{\mathrm{D}} f_{\mathrm{FD}}$, can be approximated from the frictional drag on a flat plate, which is given by

$$
P_{F D}=\frac{1}{2} \rho_{w} U^{3} A_{w e t} C_{D}
$$

where the drag coefficient, $C_{\mathrm{D}}$, may be calculated based on the 1957 ITTC line as

$$
C_{D}=\frac{0.075}{\left(\log _{10} \operatorname{Re}_{L}-2.0\right)^{2}}
$$

where $R e_{L}$ is the Reynolds number based on the ship's length. The power needed to compress a given mass flow rate of gas via a polytropic process (i.e. process where $P V^{n}=$ constant) is given by

$$
P_{\text {comp }}=\frac{\dot{m}_{g} p_{1} n}{\eta_{c} \rho_{g, 1}(n-1)}\left(\left[\frac{p_{2}}{p_{1}}\right]^{(n-1) / n}-1\right)
$$

(Sonntag et al., 2003). For an isentropic process the exponent $n$ (also called index or polytropic index) is replaced by $k$, the ratio of specific heats, which is 1.40 for air. $\dot{m}_{g}$ is the mass flow rate of gas, $p_{1}$ is the initial pressure, assumed to be 1 atm, $p_{2}$ is the pressure to which the gas needs to be compressed, which depends on the pressure beneath the hull determined by ship's draft and piping losses, $\rho_{g, l}$ is the initial density of the gas to be compressed and $\eta_{\mathrm{c}}$ is the compressor efficiency.

The mass flow rate of air needed to achieve the required volume flow rate of air beneath the hull at a pressure below the hull (assuming that the gas is cooled to $25^{\circ} \mathrm{C}$ after compression) is given by

$$
\dot{m}_{g}=q W \frac{\rho_{g, 1} p_{3}}{p_{1}}
$$

where $W$ is the width of the air lubricated region.

For a slow moving ship the pressure under the hull is assumed to be equal to the hydrostatic pressure at the draft depth, $p_{3}=\rho_{w} g D$, where $D$ is the ship's draft. Note that $p_{2}=p_{3}+\Delta p_{\text {loss }}$, and simplifying to assume nominally constant density 
through the piping, the pressure loss can be calculated from

$$
\Delta p_{\text {loss }}=\frac{\rho_{g, 3} U^{2}}{2}\left(\frac{f L_{\text {pipe }}}{d_{\text {pipe }}}+\sum K\right)
$$

where the first term in the parentheses accounts for the frictional pressure loss and the second term for the minor losses from valves, elbows, etc. The friction factor, $f$, in the first term is calculated based on the Moody chart with the assumed pipe surface roughness. The density of gas is taken as density at pressure $p_{3}$.

The volumetric gas flux, $q \mathrm{~W}$, required to achieve ALDR or PCDR at pressure $p_{3}$ can be estimated by curve fitting the data provided by Elbing et al. (2008) and Mäkiharju et al. (2010) (i.e. Fig. 2 and 3 herein). For ALDR on a smooth surface, a quadratic regression $\left(R^{2}=0.99\right)$ of the data in Fig. 2 for a speed range from 6.7 to $15.3 \mathrm{~m} / \mathrm{s}$ is given by

$$
q=0.000501 U^{2}-2.98 \cdot 10^{-5} U+0.0080
$$

For ALDR on a rough surface, a quadratic regression $\left(R^{2}=1.00\right)$ of the data in Fig. 2 for a speed range from 6.8 to $12.5 \mathrm{~m} / \mathrm{s}$ is given by

$$
q=0.00126 U^{2}-0.00755 U+0.0391
$$

For PCDR a curve fit of the data establishment flux from 5.5 to $7.5 \mathrm{~m} / \mathrm{s}$ gives a quadratic fit with $R^{2}=0.95$

$$
q=0.00476 U^{2}-0.04796 U+0.150
$$

For the PCDR maintenance flux in the same range a quadratic fit with $R^{2}=0.81$ is given by

$$
q=0.00701 U^{2}-0.0866 U+0.277
$$

Taken together, we can then derive the relationship for the power saved with air lubrication:

$$
\frac{\% P_{\text {savings }}}{100} \approx f_{F D} \frac{A_{a c}}{A_{\text {wet }}}\left(\frac{\% D_{R}}{100}\right)-\frac{P_{\text {comp }} \eta_{\text {prop }}}{P_{D} \eta_{\text {elect }}}
$$

\section{Example calculation of power savings for a typical 1,000 foot Great Lakes ship}

To evaluate the power saved as a function of ship speed for either ALDR or PCDR, we need to assign values to ship and air delivery system specific parameters. We have done so for a hypothetical Great Lakes ship similar to the M/V American Spirit (as described by Miller, 1979) operated by the American Steamship Company and shown in Fig. 4. The actual or estimated values are listed in Table 1 .

We again make the gross assumption that for ALDR, the layer persists along the entire length of the hull and that the frictional drag on the area covered is $80 \%$. If an air layer is broken into its transitional state, the efficiency of FDR may decrease to values between 20 and $80 \%$ as shown in Elbing et al. (2008). And, for PCDR, we are assuming that a multi-wave cavity will have the same gas requirements as the single wave cavity with a similar closure. 
Table 1 Parameters used in example calculation.

\begin{tabular}{|c|c|}
\hline Parameter & $\begin{array}{l}\text { Value assumed for a prototype ship similar } \\
\text { to the } M / \mathrm{V} \text { American Spirit }\end{array}$ \\
\hline Overall length, $L$ & $306 m$ \\
\hline Beam, $B$ & $32 m$ \\
\hline Draft, $D$ & $8.5 \mathrm{~m}$ \\
\hline Area of wetted hull ${ }^{1}, A_{\text {wet }}$ & $1.5 \times 10^{4} \mathrm{~m}^{2}$ \\
\hline Width of air lubricated region, $W$ & $30.5 \mathrm{~m}$ \\
\hline Length of air lubricated region, $l$ & $245 m$ \\
\hline Wetted area with air lubrication & $50 \%$ \\
\hline Speed range of interest, $U$ & 5.3 to $7.7 \mathrm{~m} / \mathrm{s}$ \\
\hline Fraction of drag due to friction, $f_{\mathrm{FD}}$ & $60 \%$ \\
\hline FDR on areas with air lubrication ${ }^{2}, \% D_{\mathrm{R}}$ & $80 \%$ \\
\hline Propulsive efficiency ${ }^{3}, \eta_{\text {prop }}$ & $65 \%$ \\
\hline Electrical generating efficiency, $\eta_{\text {elect }}$ & $90 \%$ \\
\hline Air compressor efficiency ${ }^{4}, \eta_{\mathrm{c}}$ & $65 \%$ \\
\hline Air pipe surface roughness, $\varepsilon$ & $0.05 \mathrm{~mm}$ \\
\hline Length of air pipes, $L_{\text {pipe }}$ & $15 m$ \\
\hline Diameter of air pipes, $d_{\text {pipe }}$ & $0.15 m$ \\
\hline Number of air pipes, $\#_{\text {pipes }}$ & 5 \\
\hline Minor loss coefficient in piping, $\sum K$ & 5 \\
\hline
\end{tabular}

${ }^{1}$ Calculated assuming cylindrical bow and stern, thus overestimating the wetted area.

${ }^{2}$ Estimated based on Ceccio (2010) and Elbing et al. (2008).

${ }^{3}$ Parsons et al. (2011). ${ }^{4}$ Personal communication with Continental Blower LCC indicates that assuming efficiency up to $70 \%$ is reasonable.

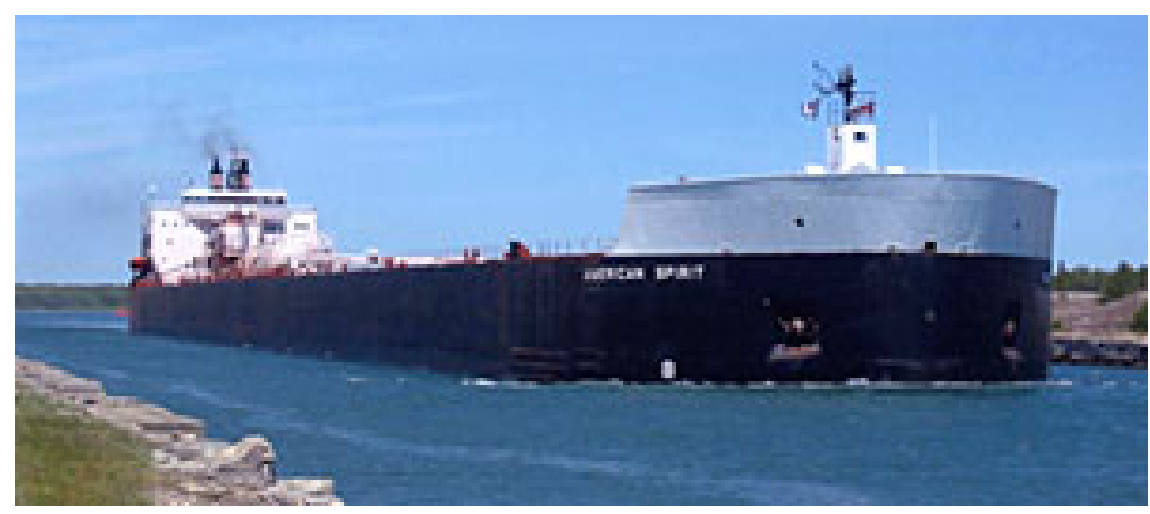

Fig. 4 The M/V American Spirit is a cargo ship operating on the U.S. Great Lakes. $L=306 \mathrm{~m}, w=32 \mathrm{~m}$ and midsummer draft $8.8 m$ (Picture from the American Steamship Company, http://www.americansteamship.com/). 
Fig. 5 to 9 show the estimated net energy savings for a variety of conditions, where all parameters are assumed to be those listed in Table 1 unless stated otherwise. The break-even point for power savings depends on three principal parameters: the ship's draft and length, and its operating speed. As the speed of the ship increases, the power savings can increase, as for ALDR the friction drag increases faster with ship speed than the required volume flux of lubricating air. Moreover, the savings increase with increasing ship length, as the benefit of the air injection extends to a greater fraction of the ship area downstream. However, the cost of pumping the air goes as the square of the draft, since an increase in draft increases both the back pressure against which the compressor or blower must work, and the required mass flux of air, as the gas volume must be compressed when injected into the higher pressure flow beneath the hull.

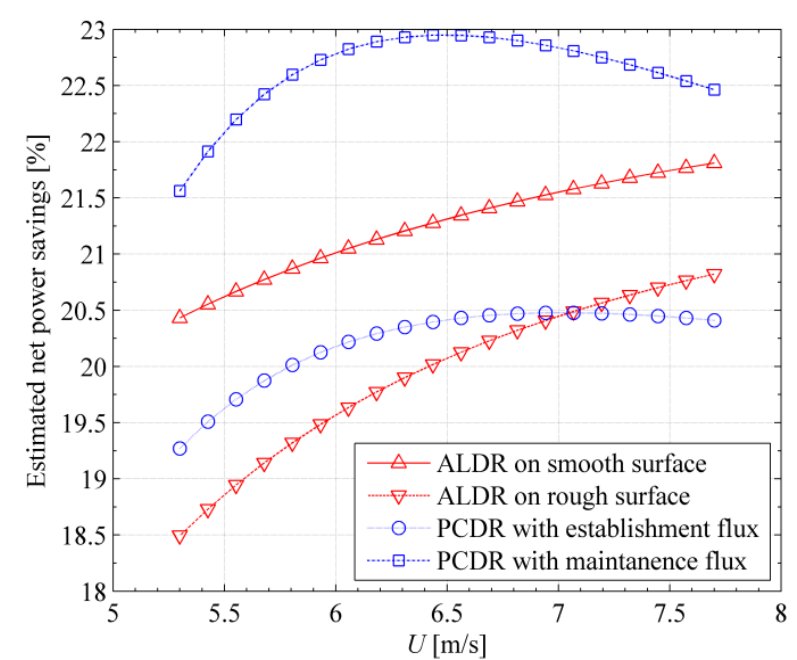

Fig. 5 Estimates of the potential net power savings for a ship similar to the M/V American Spirit. Note that the net power savings would drop to the $13 \%$ range, if for instance the piping were undersized causing a large pressure drop.

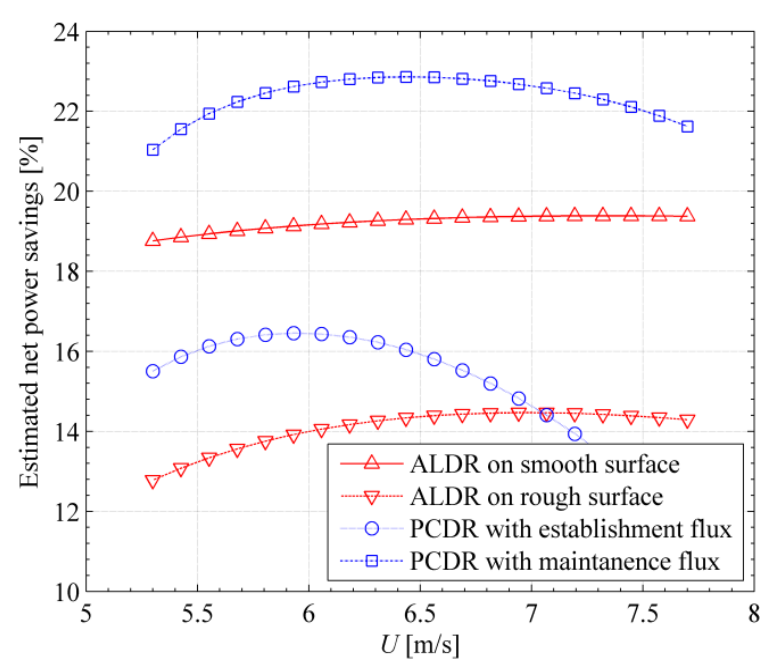

Fig. 6 Estimates of the potential net power savings with high piping losses resulting from use of only five $5 \mathrm{~cm}$ pipes.

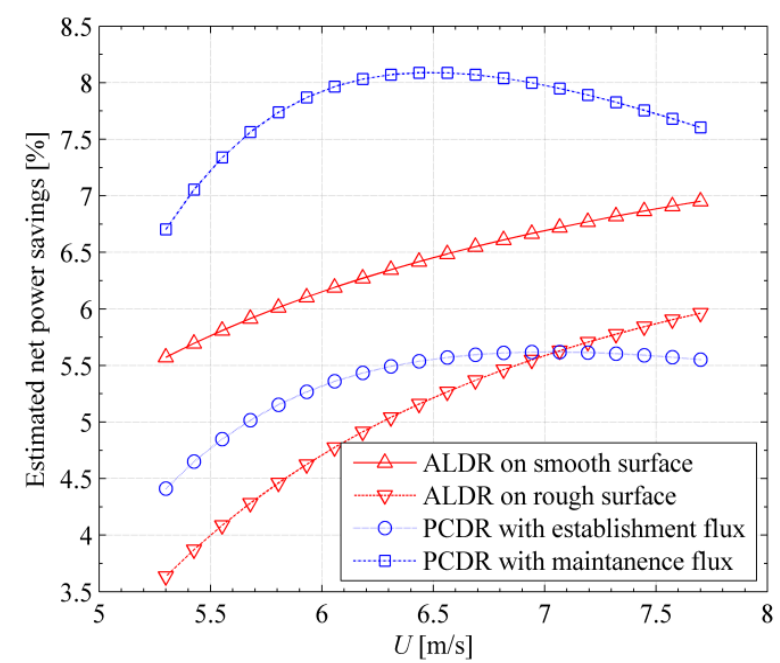

Fig. 7 Estimates of the potential net power savings if the efficiency of FDR on areas with air lubrication,

$\% D_{\mathrm{R}}$, is assumed to be only $30 \%$.

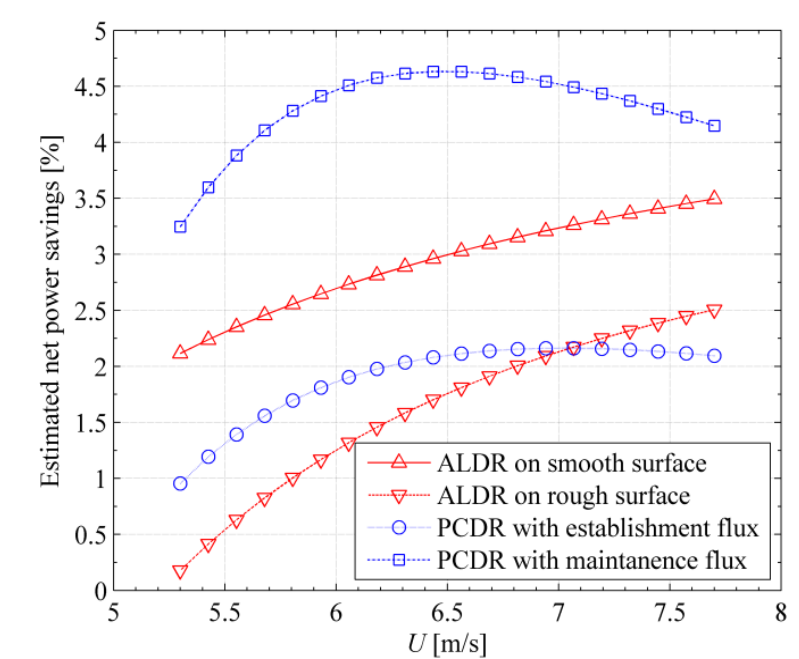

Fig. 8 Estimates of the potential net power savings if the efficiency of FDR on areas with air lubrication, $\% D_{\mathrm{R}}$, is assumed to be only $30 \%$, and length of air layer or cavity is reduced to $150 \mathrm{~m}$. This brings the fraction of wetted surface covered by air to $30 \%$, which may be more achievable for hull forms used in ocean going vessels. 


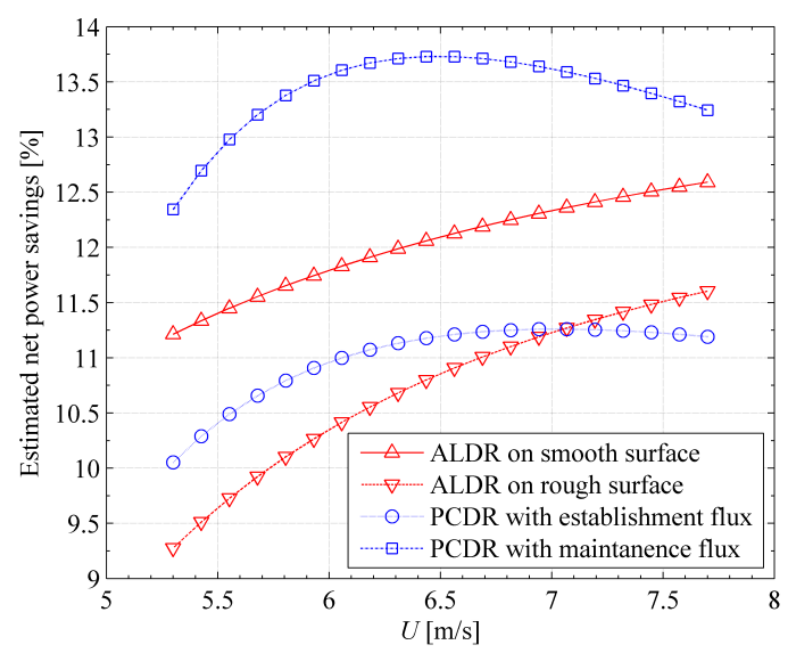

Fig. 9 Estimates of the potential net power if the efficiency of FDR on areas with air lubrication, $\% D_{\mathrm{R}}$, is assumed to be $80 \%$, and length of air layer or cavity is $150 \mathrm{~m}$.

For the conditions examined here, Fig. 5 indicates that both ALDR and PCDR could provide an overall net power savings in the range between $18 \%$ and $22 \%$. These values may be considered a best-case estimate, as there are many factors this analysis does not include, e.g. the effect of hull curvature, ship motions, and possible interactions between the injected gas and the ship's propulsors. In particular, it is likely that the gas fluxes required for both PCDR and ALDR will increase with sea state and this would likely reduce the energy savings to be between those realized with the cavity establishment and maintenance flux.

Nevertheless, these estimates are consistent with the reported savings of 4 to $7 \%$ net energy via presumably ALDR on the Pacific Seagull (Hoang et al., 2009), and net energy savings of 8 to 12\% reported by Mitsubishi Heavy Industries. In particular, for the Mitsubishi ship, after conjecturing the unknown details of the system, our method predicts maximum net energy savings of 14 or $12 \%$, for a smooth or rough hull surface respectively. Moreover, PCDR has yielded net energy savings of $15 \%$ as reported by MARIN for PCDR (Foeth, 2011), while STENA has reported resistance reductions of $20 \%$ to $25 \%$ on a $1: 12^{\text {th }}$ scale test model with PCDR (Surveyor, 2011).

\section{CONCLUSIONS}

Presented here are the results of an analysis to determine the net power saved by the application of air lubrication for conventional ships with large flat bottoms. Both Air Layer Drag Reduction and Partial Cavity Drag Reduction were considered, and data from recent controlled experiments were used to estimate the required volumetric fluxes of injected air. After employing a number of important assumptions, we were able to determine the net power saved through the application of ALDR or PCDR. In fact, a sample calculation was presented for a conventional ship similar to the M/V American Spirit. The results presented for this case show possible net energy savings on the order of $10 \%$ to $20 \%$. And, while these estimates represent a "best case" application of air lubrication, they are consistent with net energy savings reported for recent sea trials.

\section{ACKNOWLEDGEMENTS}

Research funded in part by the Great Lakes Maritime Research Institute, supported by the U.S. Department of Transportation, Office of the Secretary, Grant \# DTMA1-G-10001, and by the Office of Naval Research, Program Manager Patrick Purtell grant \# N00014-08-1-0215.

\section{REFERENCES}

Amromin, E. and Minize, I., 2003. Partial cavitation as drag reduction technique and problem of active flow control. Marine Technology, 40(3), pp.181-188. 
Arndt, R.E.A., Hambleton, W.T., Kawakami, E. and Amromin, E.L., 2009. Creation and maintenance of cavities under horizontal surfaces in steady and gust flows. Journal of Fluids Engineering, 131(11).

Butuzov, A., Sverchkov, A., Poustoshny, A. and Chalov, S., 1999. State of art in investigations and development for the ship on the air cavities. International Workshop on Ship Hydrodynamics. China, pp.1-14.

Butuzov, A.A., 1967. Artificial cavitation flow behind a slender wedge on the lower surface of a horizontal wall. Fluid Dynamics, 2(2), pp.56-58.

Ceccio, S.L., 2010. Friction drag reduction of external flows with bubble and gas injection. Annual Review of Fluid Mechanics, 42, pp.183-203.

Choi, K.-S., Prasad, K.K. and Truong, T.V. eds., 1996. Emerging techniques in drag reduction. Mechanical Engineering Publications Limited.

Elbing, B.R., Winkel, E.S., Lay, K.a., Ceccio, S.L., Dowling, D.R. and Perlin, M., 2008. Bubble-induced skin-friction drag reduction and the abrupt transition to air-layer drag reduction. Journal of Fluid Mechanics, 612, pp.201-236.

Foeth, E.-J., 2011. Projects prove that air cavities reduce ship resistance. Report, MARIN's news magazine, 16 . August.

Gokcay, S., Insel, M. and Odabasi, A.Y., 2004. Revisiting artificial air cavity concept for high speed craft. Ocean Engineering, 31(3-4), pp.253-267.

Hoang, C.L., Toda, Y. and Sanada, Y., 2009. Full scale experiment for frictional resistance reduction using air lubrication method. Proc. of the Nineteenth International Offshore and Polar Engineering Conference. pp.812-817.

Kodama, Y., Kakugawa, A., Takahashi, T. and Kawashima, H., 2000. Experimental study on microbubbles and their applicability to ships for skin friction reduction. International Journal of Heat Fluid Flow, 21(5), pp.582-588.

Kawashima, H., Kodama, Y., Hinatsu, M., Hori, T., Makino, M., Ohnawa, M., Takeshi, H., Sakoda, M., Kawashima, H. and Matsuno, F., 2007. A research project on application of air bubble injection to a full scale ship for drag reduction. 5th Joint ASME/JSME Fluids Engineerign Conference. San Diego, CA.

Latorre, R., 1997. Ship hull drag reduction using bottom air injection. Ocean Engineering, 24(2), pp.161-175.

Lay, K.A., Yakushiji, R., Mäkiharju, S., Perlin, M. and Ceccio, S.L., 2010. Partial cavity drag reduction at high Reynolds numbers. Journal of Ship Research, 54(2), pp. 109-119.

Miller, R.H., 1979. Great lakes thousand footers. Proceedings, Joint Eastern Canada and Great Lakes and Great Rivers Sections of Society of Naval Architects and Marine Engineers Meeting. Toronto, Ontario 18-May.

Madavan, N.K., Deutsch, S. and Merkle, C.L., 1985. Measurements of local skin friction in a microbubble modified turbulent boundary layer. Journal of Fluid Mechanics, 156, pp.237-256.

Matveev, K.I., 2003. On the limiting parameters of artificial cavitation. Ocean Engineering, 30(9), pp.1179-1190.

Mäkiharju, S., Elbing, B.R., Wiggins, A., Dowling, D.R., Perlin, M. and Ceccio, S.L., 2010. Perturbed Partial Cavity Drag Reduction at High Reynolds Numbers. Proc. $28^{\text {th }}$ Symp. on Naval Hydrodynamics. Pasadena, CA.

Mäkiharju, S., 2012. The dynamics of ventilated partial cavities over a wide range of Reynolds Numbers and Quantitative $2 D$ X-ray densitometry for multiphase flow. PhD. University of Michigan.

Mizokami, S., Kawakita, C., Kodan, Y., Takano, S., Higasa, S. and Shigenaga, R., 2010. Experimental study of air lubrication method and verification of effects on actual hull by means of sea trial. Mitsubishi Heavy Industries Technical Review, 47(3), pp.41-47.

Proceedings of the 2nd International Symposium on Seawater drag reduction, 2005. Busan, Korea 23-26 May 2005.

Proceedings of the International Symposium on Seawater drag reduction, 1998. Newport, Rhode Island 22-23 July 1998.

Parsons, M.G., Singer, D.J. and Denomy, S.J., 2011. Integrated electric plants in future great lakes self-unloaders. Journal of Ship Production and Design, 27(4), pp.169-185.

Sonntag, R.E., Borgnakke, C. and Van Wylen, G.J., 2003. Fundamentals of thermodynamics. Wiley.

Sanders, W.C., Winkel, E.S., Dowling, D.R., Perlin, M. and Ceccio, S.L., 2006. Bubble friction drag reduction in a highReynolds-number flat-plate turbulent boundary layer. Journal of Fluid Mechanics, 552, pp.353-380.

Surveyor, 2011. Airship of the sea. Surveyor, A Quarterly Magazine from ABS, pp.10-15. 